\title{
Do three-spined sticklebacks avoid consuming copepods, the first intermediate host of Schistocephalus solidus? - an experimental analysis of behavioural resistance
}

\author{
C. WEDEKIND and M. MILINSKI
}

Abteilung Verhaltensökologie, Zoologisches Institut, Universität Bern, CH-3032 Hinterkappelen, Switzerland

(Receized 22 September 1995 ; revised 24 October $1995 ;$ accepted 24 October 1995)

SUMMARY

Many parasites that use intermediate hosts are transmitted to the next host through predation. If the next host's fitness is strongly reduced by the parasite, it is under selection either to recognize and avoid infected intermediate hosts or to exclude that prey species from its diet when alternative prey are available. We investigated the predator-prey interaction between laboratory bred three-spined sticklebacks (Gasterosteus aculeatus), the second intermediate host of the cestode Schistocephalus solidus, from 2 parasitized and 1 unparasitized population, and different prey types: infected and uninfected copepods and size-matched Daphnia as alternative prey. Copepods with infective procercoids were more active, had a lower swimming ability and were easier to catch than uninfected controls. The sticklebacks preferred moving copepods. Therefore parasitized copepods were preferentially attacked and consumed. There was no effect of the sticklebacks' parent population being parasitized or not. 'The sticklebacks switched from Daphnia to (uninfected) copepods in the course of a hunting sequence; this switch occurred earlier in smaller fish. With this strategy the fish maximized their feeding rate: Daphnia were easier to catch than copepods but increasingly difficult to swallow when the stomach was filling up especially for smaller fish. However, there was no indication that sticklebacks from infected populations either consumed Daphnia rather than copepods or switched later in the hunting sequence to consuming copepods than fish from an uninfected population. Thus, sticklebacks did not avoid parasitized prey although $S$. solidus usually has a high prevalence and causes a strong fitness reduction in its stickleback host.

Key words: Schistocephalus solidus, copepod, Gasterosteus aculeatus, behavioural changes, predation risk, optimal diet, population.

\section{INTRODUCTION}

Parasites that need their intermediate host to be preyed upon by their next host often alter the intermediate host's conspicuousness, e.g. its coloration and/or behaviour, and its fleeing ability and motivation (Holmes \& Bethel, 1972; Moore, 1984, 1995; Dobson, 1988; Milinski, 1990; Moore \& Gotelli, 1990; Poulin, 1994). Physiological mechanisms through which this manipulation can be achieved have only recently started to be understood (Holmes \& Zohar, 1990; Thompson \& Kavaliers, 1994). There are relatively few examples of manipulated intermediate hosts that are indeed preferentially preyed upon (e.g. Moore, 1983; Poulin, Curtis \& Rau, 1992). This is not necessarily expected under coevolution between the parasite and the final host (May \& Anderson, 1990). The final host could avoid becoming parasitized by avoiding consumption of parasitized prey (Moore, 1983; Combes, 1991; Lozano, 1991 ; Lafferty, 1992 ; Hart, 1994). Only few examples exist of hosts that avoid either parasitized prey (e.g. Hulscher, 1973; Keymer, Crompton \& Sahakian, 1983) or risky food patches as ungulates do when they avoid grazing near recently dropped faeces (Hart, 1994).
Avoiding parasitized prey could be called behavioural resistance. In order for any host resistance to evolve, its cost must be less than the cost of parasitic infection in terms of overall reproductive success (Minchella, 1985; Keymer \& Read, 1991). Although the cost of resistance is generally not easy to measure (Minchella \& LoVerde, 1983), the well-established optimal diet theory (Emlen, 1966; MacArthur \& Pianka, 1966; Stephens \& Krebs, 1986) can be used to determine the cost of avoiding potentially parasitized prey (Lafferty, 1992). For a prey type to be included in the optimal diet, the amount of energy that the predator gains per unit handling time that is needed to extract that energy must exceed a threshold; this threshold depends on the profitability and the availability of the more profitable prey types that are already in the diet (Stephens \& Krebs, 1986). By reducing the intermediate host's fleeing ability and motivation the parasite increases its present host's value as prey. Enhanced conspicuousness plays a secondary role, because it increases predation risk only if the intermediate host is already included in the next host's optimal diet. The cost of avoiding parasitized prey can be calculated in terms of missed net energy gain. If the parasite has a negligible negative effect on the final host's fitness as 
is the case, e.g. for the acanthocephalan Plagiorhynchus cylindraceus that alters behaviour of its intermediate host to parasitize starlings (Moore, 1983) or for the cestode Schistocephalus solidus that parasitizes birds when they consume infected threespined sticklebacks (Smyth, 1985), predators may actually benefit from their parasites (Lafferty, 1992). If, however, the parasite has a severe effect on the next host's fitness and if its prevalence in the intermediate host population is high enough that the next host is likely to be parasitized when it consumes potentially infected prey, the next host is predicted to evolve selective feeding on uninfected prey (Lafferty, 1992).

The conditions for the evolution of behavioural resistance through selective feeding seem to be fulfilled for S. solidus' second intermediate host, the three-spined stickleback, Gasterosteus aculeatus, that has to consume $S$. solidus' first intermediate host, copepods, to become parasitized. The procercoid of $S$. solidus reaches its infective stage within about 10 days in a copepod, e.g. Cyclops sp. (Smyth, 1985). In the stickleback, the procercoid bores through the gut into the body cavity, where it grows as plerocercoid to a size that sometimes surpasses that of its host (Arme \& Owen, 1967; personal observation). It reaches infectivity for the definitive host within 2-3 months (Orr \& Hopkins, 1969). During this time it is more efficient in its energy transformation than is its host and causes a considerable energy drain from the fish (Walkey \& Meakins, 1970; Pascoe \& Mattey, 1977). Although they have an increased need for energy, parasitized sticklebacks are restricted in their gut capacity (Milinski, 1985; Cunningham, Tierney $\&$ Huntingford, 1994). This and their inferiority as competitors appears to trigger their efficient prey size selection (Milinski, 1984; Cunningham et al. 1994; Ranta, 1995). Infected fish do not only tradeoff foraging for predator avoidance (Giles, 1983, 1987) but also seem to be manipulated by the parasite when the plerocercoid approaches infectivity (Milinski, 1985, 1990; Dawkins, 1990; Tierney, Huntingford \& Crompton, 1993).

Reproduction of parasitized sticklebacks is significantly affected in females. Their oocyte maturation is delayed and only lightly infected females can spawn (Arme \& Owen, 1967; Meakins, 1974; McPhail \& Peacock, 1983; Pennycuick, 1971 a). Heavily parasitized males, even those with nests, do not reproduce (Arme \& Owen, 1967). Thus, the cost of an $S$. solidus infection to a stickleback in terms of overall reproductive success seems to be high enough that there should be selection for behavioural resistance.

Perhaps the risk of becoming parasitized is nevertheless low because the prevalence of $S$. solidus is low in copepods. About $9^{\circ}$ of oyclops strenuus from Loch Lomond were parasitized with procercoids of Diphyllobothrium spp. (Pasternak, Hun- tingford \& Crompton, 1995), which means that consumption of parasitized prey is inevitable for an unselective fish. There is indirect evidence for the risk of infection with $S$. solidus of sticklebacks that consume copepods. The prevalence of $S$. solidus in sticklebacks is usually high in natural populations, e.g. $100 \%$ (Hopkins \& Smyth, 1951 ; Arme \& Owen, 1967; Threlfall, 1968), 27\% (Chappell, 1969), 85-99\% (Pennycuick, 1971 $a, b$ ), $53 \%$ (McPhail \& Peacock, 1983). It must have thus been risky for sticklebacks to consume copepods. Selection for behavioural resistance should be strong.

Does the stickleback have the opportunity to distinguish non-infected from infected copepods? Cyclops sp. that were infected with $S$. solidus differed from uninfected controls in their response to disturbance and their degree of activity, but they were not detected to be preyed upon significantly more often by sticklebacks than controls (Urdal, Tierney \& Jakobsen, 1995). Also Cyclops vernalis that were infected with procercoids of Eubothrium salvelini were more active than uninfected controls but were more heavily preyed upon by brook trout, Salvelinus fontinalis, than were controls (Poulin et al. 1992). Infected copepods offer in both cases the cues by which they can be distinguished from uninfected ones.

Our aims were to test experimentally whether (1) infected copepods have a higher prey value because of a potentially reduced fleeing ability, (2) laboratory bred three-spined sticklebacks from 2 populations with $S$. solidus attack infected copepods less frequently than non-infected ones, and copepods less frequently than size-matched Daphnia as compared to sticklebacks from a non-infected population, (3) the differential attack is influenced by the behaviour that is altered in infected copepods. Following the optimal diet approach, we used juvenile sticklebacks for which copepods have the optimal prey size; larger fish should catch them only when they have limited choice. Since the majority of infections are established under natural conditions in spring (Meakins \& Walkey, 1973), juveniles would outnumber adult sticklebacks anyway, and the parasite may be adapted to complete its life-cycle with this size-class.

\section{MATERIALS AND METHODS}

\section{Hosts and parasite}

The parasite (Schistocephalus solidus) was cultured in vitro using techniques modified from Smyth (1954). Copepods (Macrocyclops albidus), the first intermediate host of $S$. solidus, were cultured and infected using techniques modified from Orr \& Hopkins (1969). About 2 weeks p.i. the copepods were screened for procercoids with cercomers (i.e. the infective stage) under a microscope. If not described otherwise unexposed copepods to be used in an 
experiment were treated in the same way. Only copepods without eggsacks were used for experiments. Experiments were performed in 1992 and 1993.

Three-spined sticklebacks (Gasterosteus aculea$t u s)$, the second intermediate host of S. solidus, were offspring of adults that we had caught from 3 different populations. In two of the populations, i.e. Bochum and Düsseldorf (both Germany, about $120 \mathrm{~km}$ apart) $S$. solidus infections of sticklebacks had been observed for many years, in the third population (Roche, Switzerland, about $500 \mathrm{~km}$ from Bochum) S. solidus has never been found. We used clutches that were produced in Bern by several sticklebacks from each population. The eggs were removed after fertilization and hatched artificially with established procedures (Bakker, 1986). The offspring of fish from the 3 populations were raised simultaneously in sib-groups under standardized conditions. They were fed the same diet which consisted of Artemia, Daphnia, Tubifex and (noninfected) copepods. The sticklebacks were used for experiments when they had a size (between 1.4 and $2.2 \mathrm{~cm}$ standard length) for which copepods are an optimal prey with respect to size (Toscanelli, 1992). Each stickleback was used only once and for only one experiment (except for the control after experiment 1).

\section{Experiment 1 : choice by sticklebacks}

This experiment was performed to test (1) whether sticklebacks attack infected and uninfected copepods differently, (2) whether such a distinction could depend on the existence of the parasite in the sticklebacks' parent-population, (3) whether the sticklebacks' attack rate depends on the copepods' movements which are potentially affected by the parasite, (4) whether the sticklebacks' choice of an alternative prey (Daphnia magna) when offered besides copepods could depend on the existence of the parasite in the sticklebacks' parent-population.

On day 1 fish of a similar length were selected (by M.M.) from each population sib-group. Each fish was transferred (by C.W.) to a coded individual tank $(18 \times 12 \times 11.5$ (high) $\mathrm{cm}$, water-level $8.5 \mathrm{~cm})$ which contained a piece of moss, (Fontinalis sp.); the tanks were illuminated from above by fluorescent tubes and were visually separated from each other by grey partitions. The experimenter (M.M.) who handled the fish thereafter did not know the code. On days 2 , 3 and 4 each fish received 15 copepods from C.W. (so that M.M. could not see eventual differences in the fishes' hunting for copepods) in the morning; in the afternoon each fish was caught with a glass-pipe that contained water, removed from its tank for a min during which 15 Daphnia of about copepod size were placed in the fish's tank, and returned to its tank. By this procedure the fish became accustomed to being caught and transferred. In the morning of day 5, each fish was fed 10 Daphnia of the usual size.

The experimental tank had the same size as the fishes' individual tanks and contained also a piece of moss close to one short wall. In front of the other short wall there was a transparent Plexiglas cell that was divided into 7 adjacent compartments, each with a base of $1 \times 1 \mathrm{~cm}$ (Milinski \& Heller, 1978). The water level in the cell was $1 \mathrm{~cm}$ lower than that in the tank $(8 \cdot 5 \mathrm{~cm})$. Before a trial, compartments 2 and 3 were each supplied with 3 infected copepods, compartments 5 and 6 were each supplied with 3 size-matched uninfected copepods. After $5 \mathrm{~min}$ a stickleback was transferred within the glass-pipe to the experimental tank and released above the moss.

The fish approached the cell and attacked the copepods usually within $1 \mathrm{~min}$. The fish's behaviour was recorded with a video camera that was placed in front of the short wall to which the cell was attached. This camera recorded both the movements of the copepods and the choice of compartment by the fish for $3 \mathrm{~min}$ starting with the first bite. The experimenter observed simultaneously only the bites of the fish on a video screen and spoke each event of a bite on the audio-channel of the frontal camera's recorder. The video screen displayed the view of a second video camera that viewed exactly along the front wall of the cell so that only the bites of the fish but not its choice of compartment could be seen by the experimenter (the protocol of bites was therefore unbiased by the fish's choice). Thereafter the fish was exchanged for a fish from another population and the trial was repeated. After a fish of the third population had been tested with the same set of 6 infected and 6 uninfected copepods, the copepods were removed to be used for Experiment 2 in the late afternoon. Another set of 6 infected and 6 uninfected copepods was transferred to the Plexiglas cell, the sides were exchanged to neutralize any undetected asymmetry of the set-up. Another set of 3 sizematched fish, 1 of each of the 3 populations, was tested as described above. Each such set of naive fish was tested with a new set of copepods. The sequence of the 3 fish was varied in each set to neutralize any effect of time (e.g. hunger) on the behaviour of the fish. Because all fish in the test had to have the same age, we used offspring from 1 pair of sticklebacks from each population in this experiment.

To test whether sticklebacks avoid copepods when alternative prey is available, another series of trials was performed as described above except that 2 compartments of the cell contained 3 Daphnia each instead of infected copepods. The sticklebacks were thus offered a choice between 6 uninfected copepods and 6 size-matched Daphnia (without parthenogenetic eggs). Daphnia selected but not used for the experiment were $1.33 \pm 0.03$ (mean \pm s.e.) $\mathrm{mm}$ high (without the spine), $n=52$, on one day and $1.36 \pm$ $0.04 \mathrm{~mm}, n=31$, on another experimental day. 
Copepods from the latter day were $1.51 \pm 0.05 \mathrm{~mm}$ high (whole 'body' without the furcal rami), $0.95 \pm$ $0.03 \mathrm{~mm}$ long (oval part of 'body' including the 4th thoracic segment), $n=14$. Sets of size-matched naive fish of the 3 populations were tested each with a new set of copepods and Daphnia. Because the sib-groups from the 3 populations differed in number, we could use only 2 or 1 fish for a few (out of 20) sets. After a trial the fish was transferred to its tank where it was starved for $24 \mathrm{~h}$ and thereafter supplied with 20 Daphnia of the size that had been used before. The Daphnia, in $50 \mathrm{ml}$ of water, were poured into the tank. The time required by the fish to catch and finally swallow each of its first 6 Daphnia was recorded.

\section{Experiment 2 : hunting copepods and Daphnia by sticklebacks}

This experiment was performed to investigate the sticklebacks' choice and success when they could actually hunt (as opposed to Exp. 1) mixtures of either infected and uninfected copepods or uninfected copepods and size-matched Daphnia. Although the method was independently developed it turned out to be similar to the methods used by Poulin, Curtis \& Rau (1992) and Urdal et al. (1995).

(a) The first series of the experiment was performed after Exp. 1 with the copepods and the Daphnia that had been removed from the Plexiglas cell. Before Exp. 1, fish of each of the 3 populations were selected randomly to be used either in Exp. 1 or in Exp. 2. The experimental tank from Exp. 1 was used after the Plexiglas cell and the plant had been removed. Before a trial either 9 infected and 9 uninfected copepods (for one trial we had only 6 infected and 6 uninfected copepods) or 9 Daphnia and 9 uninfected copepods were transferred to the experimental tank. After $5 \mathrm{~min}$ a stickleback was transferred within the glass-pipe to the experimental tank. The behaviour of the stickleback was videorecorded until it had consumed about half of the prey items. The trial was terminated by removing the fish. The sticklebacks that had hunted on infected and uninfected copepods were anaesthetized in MS 222 and killed by decapitation. Both the copepods removed from the fish and from the tank were squeezed under the microscope to determine their infective status. Also Daphnia and uninfected copepods were used only once.

(b) In the second series of the experiment only offspring from the Düsseldorf sticklebacks were tested (mean \pm S.E. length: $1.76 \pm 0.09 \mathrm{~cm}$ ). The fish were offspring from another pair of sticklebacks as the one used for (a). They had no experience with copepods (they had been reared only on Artemia). Ten infected and 10 uninfected size-matched copepods were transmitted to an experimental tank $(25 \times 15 \times 15$ (high) $\mathrm{cm}$, water level $13 \mathrm{~cm})$. After
$15 \mathrm{~min}$ (or earlier if it had consumed 10 copepods) the fish was removed and the infective status of the remaining copepods was determined under the microscope.

(c) In the final series of the experiment only offspring from the Bochum sticklebacks were tested (mean \pm S.E. length: $2 \cdot 16 \pm 0.08 \mathrm{~cm}$ ) under more natural conditions. The fish were offspring from another pair of sticklebacks as the one used for (a). They had been reared as the fish in (b). Each experimental tank (size as in Exp. 1, but equipped with sand and Vallisneria plants as a refuge) was supplied with 15 copepods that had been exposed to coracidia 4 weeks ago and with 15 unexposed copepods. After 2 weeks a single stickleback was transferred to each tank. After $15 \mathrm{~min}$ the fish was removed, anaesthetized, killed and the infective status of both the copepods from its gut and those that had remained in the tank was screened under the microscope.

\section{Experiment 3: hunting copepods by a human}

This experiment was performed to test whether an untrained predator can catch one type of copepod (infected or uninfected) more easily and therefore selects that type. Thirty copepods that had been exposed to coracidia were transferred to a white plastic box $(22.5 \times 10 \times 5.5$ (high) $\mathrm{cm}$, water level $2 \mathrm{~cm}) 27$ days p.i. After $30 \mathrm{~min}$ a person who was not used to hunt copepods tried to catch single animals with a pipette (opening $2.5 \mathrm{~mm}$ ). A second person determined the size (small, medium, large) and the infective state (whether infected; number of procercoids) of each copepod that had been caught. Both persons (B.S. and S.L.) were naive with respect to the hypothesis. In a second trial 106 copepods were transferred to the box and the procedure was repeated.

\section{Experiment $4:$ infected and uninfected copepods in a current}

This experiment was performed to investigate the behaviour of infected, exposed but not infected, nonexposed handled and non-exposed unhandled copepods in a water current. Exposed copepods were screened under the microscope for procercoids on day 16 p.i. Those which were not infected were called 'control 1'. Unexposed copepods that had been maintained in the same way except for being exposed to coracidia were either 'screened' under the microscope ('control 2') or not ('control 3'). Thereafter each copepod was transferred singly to a well (water volume $2 \mathrm{ml}$ ) of an ELISA plate where it stayed until the start of the experiment. Transfer and coding of all copepods was done by a person (M.F.) that was naive concerning the kind of treatment of each group. This ensured that the experimenter (C.W.) was thereafter naive. 
A plastic pipe (diameter $2.5 \mathrm{~cm}, 100 \mathrm{~cm}$ long) was cut in half longitudinally and fixed horizontally on a table so that its cross-sectional view became $\mathrm{L}$ shaped. Tap water flew through this channel $(7.8 \mathrm{l} / \mathrm{h}$, $7 \mathrm{~mm}$ water level in the U). The central part $(55 \mathrm{~cm})$ of the channel had a cross-sectional net $(0.5 \mathrm{~mm}$ mesh-width) at each end. The current in this central part appeared very homogeneous and free from vortices when tested with coloured water. Single copepods were released from a pipette close to the upstream net of the central part. The time the copepod needed to touch the downstream net was recorded. Observations verified that this time is affected by the copepod's bouts of swimming upstream and its maintaining position on the substrate.

\section{Experiment 5 : reaction to predation}

This experiment was performed to investigate the reaction of infected and uninfected copepods to simulated predation. The copepods that had been used in Exp. 4 were transferred to ELISA plates and coded anew so that the experimenter (C.W.) did not know the origin of any copepod. In addition, 20 copepods from the infected group and the 3 control groups that had not been tested in the channel of Exp. 4 were used. The copepods were fed in the ELISA plates and remained there for 1 day until Exp. 5.

The test tank $(38 \times 20 \mathrm{~cm}$, water level $2 \mathrm{~cm})$ contained aged water from an aquarium. A black grid (size of each unit $4 \mathrm{~mm}$ ) on white paper lay underneath the tank. Single copepods were pipetted from the ELISA plate (in a way that they had no opportunity for escape behaviour) into the centre of the tank and their behaviour was observed until they rested either at the surface or on the bottom of the tank. Thereafter an attack by a fish was simulated by moving remotely a dried and varnished three-spined stickleback (standard length $1.8 \mathrm{~cm}$ ) that had been attached to a stiff piece of wire slowly toward a side of those copepods that rested on the bottom. From a distance of $1 \mathrm{~cm}$ the fish 'attacked' the copepod by a quick move until it could have touched the prey. The copepod's flight behaviour and distance was recorded. Some of the copepods that rested on the bottom could have been infected and would possibly reveal this fact by their reaction to predation. Note that the experimenter (C.W.) was still naive with respect to copepod class when he attacked only those copepods that rested on the bottom.

\section{RESLLTS}

\section{Experiment 1 : choice by sticklebacks}

Did the sticklebacks attack infected and uninfected copepods at different rates? The sticklebacks' bites (i.e. snout contacts with the Plexiglas cell) were clearly directed to copepods within the cell. Because we used 3 fish, 1 from each population, for each set that consisted of 6 infected and 6 uninfected copepods, we start by treating each of the 5 different copepod sets as a statistical unit. The infected copepods were attacked significantly more often than the uninfected ones (Fig. 1A) (repeated measures ANOVA: $\mathrm{F}=10.02, \quad$ D.F. $=1, n_{1}=n_{2}=5, \quad P=$ $0.03)$. Is this preference related to a difference in activity between infected and uninfected copepods? The duration of active swimming of the 3 copepods in each of the 4 compartments of the cell was determined for each min, i.e. the copepod-seconds of swimming per min. In this case each group of 3 copepods per compartment was our statistical unit. Infected copepods spent a greater proportion of time active than uninfected ones (Fig. 1B) (ANOVA: $\mathrm{F}=6.64$, D.F. $=1, n_{1}=10, n_{2}=10, P<0.02$ ).

Did the sticklebacks prefer to attack active copepods? For each fish we can estimate the correlation between the activity of the copepods in each compartment in each min and the number of the fish's bites directed towards these copepods both for the infected (6 pairs of data points: 2 compartments $\times 3 \mathrm{~min}$ ) and the uninfected copepods ( 6 pairs of data points: 2 compartments $\times 3 \mathrm{~min}$ ). Here each fish is a statistical unit. The average Pearson correlation coefficient between copepod activity and number of bites of the 15 sticklebacks was significantly greater than 0 both when they attacked the infected (one-sample $t$-test, two-tailed: $t=5 \cdot 66$, D.F. $=14, P \ll 0 \cdot 001)$ and the uninfected copepods $(t=$ $2.59, P=0.02$ ) (Fig. 1 C). Thus, the predation risk increased with activity in both the infected and the uninfected copepods. Moreover, the infected copepods received significantly more bites per unit activity than the uninfected ones (Fig. 1D) (repeated measures ANOVA: $\mathrm{F}=9.03$, D.F. $=1, n_{1}=10, n_{2}=$ $10, P<0.015$ ).

Do the sticklebacks from infected populations (Bochum, Düsseldorf) avoid infected copepods when compared with fish from an uninfected population (Roche)? There is no significant difference in the proportion of bites directed toward the infected copepods neither among the 3 populations (ANOVA: $\mathrm{F}=0.69$, D.F. $=2, P=0.52$ ) nor when fish from Roche were compared with fish from Bochum and Düsseldorf ( $F=0.15$, D.F. $=1, P=$ $0.70)$ (Fig. 2 A). Furthermore, the fish from the two infected populations attacked the copepods (attacks on infected and uninfected copepods combined) significantly more often than did fish from the uninfected population (Fig. 2B) (ANOVA: $F=$ 5.49 , D.F. $=1, P<0.04$ ); they should have attacked them less often to avoid the risk of parasitization.

Did sticklebacks attack uninfected copepods and size-matched Daphnia at different rates? There was no significant difference in the number of attacks 

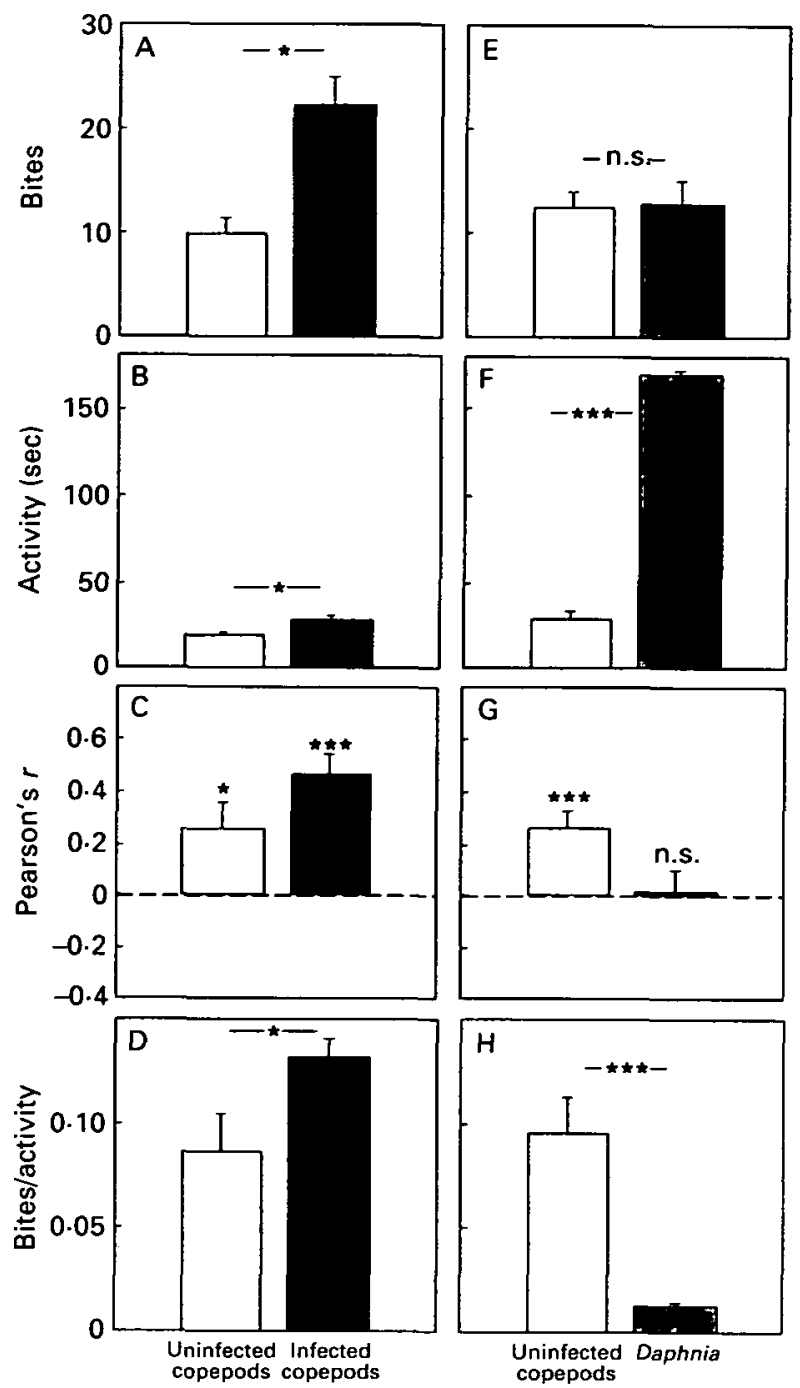

Fig. 1. Choice of sticklebacks either between uninfected and infected copepods or between uninfected copepods and Daphnia. (A) Mean +s.E. number of bites to uninfected and infected copepods; (B) mean + S.E. activity of uninfected and infected copepods measured as sum of time $(\mathrm{sec})$ that the 3 prey items in a

compartment were active/min; (C) mean + S.E. Pearson correlation coefficients between activity of prey items in each compartment in each $\mathrm{min}$ and the number of a fish's bites on these prey, i.e. uninfected and infected copepods; (D) mean +s.E. number of bites/sum of activity of prey items/compartment directed to uninfected and infected copepods; $(\mathrm{E}-\mathrm{H})$ analogous plots for the trials with uninfected copepods and Daphnia. Asterisks indicate significant differences: ${ }^{*} P<$ 0.05 , ** $P<0.01,{ }^{* * *} P<0.001$.

received between Daphnia and copepods (Fig. 1 E) (ANOVA: $\mathrm{F}=0.01$, D.F. $=1, P=0.93, n_{1}=n_{2}=$ 20), although Daphnia were a greater proportion of time active than uninfected copepods (Fig. 1F) (ANOVA: $\mathrm{F}=1087.79$, D.F. $=1, P \ll 0.001, n_{1}=40$ Daphnia groups, $n_{2}=40$ copepod groups).

Did the sticklebacks prefer to attack active prey items? The average Pearson correlation coefficient between prey activity and number of bites of 45
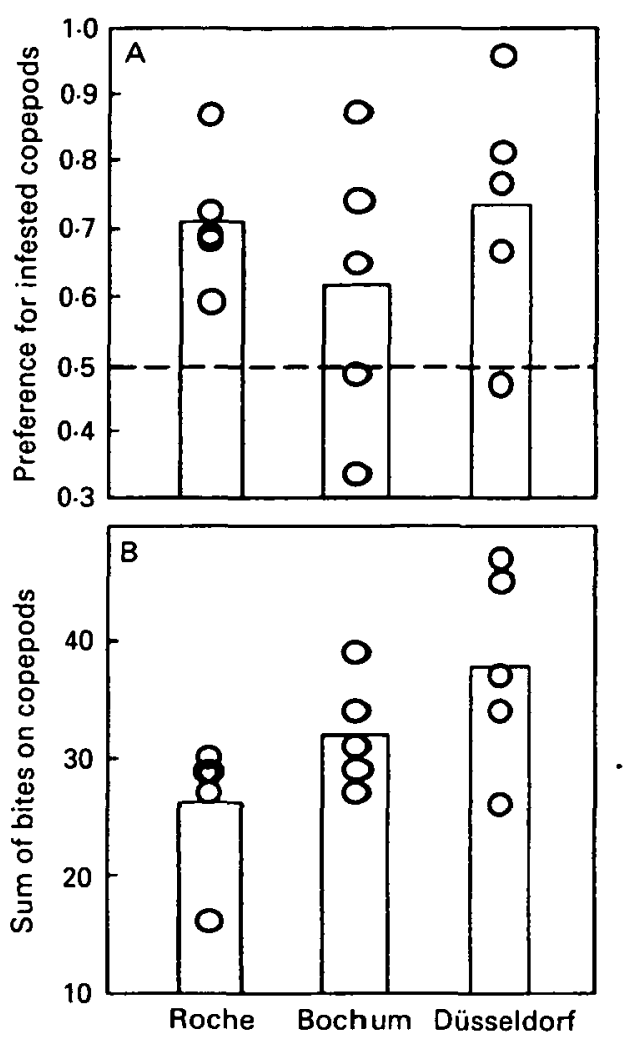

Fig. 2. (A) Proportion of bites on infected copepods and (B) sum of bites on uninfected and infected copepods by 5 sticklebacks bred from each of 3 populations, i.e. Roche (no Schistocephalus solidus), Bochum and Düsseldorf (both with $S$. solidus); bars give means, stippled line depicts no preference.

sticklebacks was significantly greater than 0 when they attacked the uninfected copepods (one-sample $t$-test, two-tailed: $t=3.81$, D.F. $=41, P<0.001$ ) but was not significantly different from 0 when they attacked the Daphnia ( $t=0 \cdot 16$, D.F. $=39, P=0.87$ ) (Fig. $1 \mathrm{G}$ ). Thus, the predation risk increased with activity only in copepods. Because Daphnia moved almost always there was probably not enough variation that could be used to detect a correlation between motion and predation risk. The copepods received significantly more bites per unit activity than the Daphnia (Fig. $1 \mathrm{H}$ ) (ANOVA: F = 25.65, D.F. $=1, P<0.0001, n_{1}=20$ Daphnia sets, $n_{2}=20$ copepod sets).

On the next day the sticklebacks were supplied with 20 Daphnia in their individual tanks. The time the fish needed to consume one Daphnia (averaged from the 2 nd to the 6 th item, the time needed to consume the first Daphnia was not used because there was no well-defined start) correlated negatively with the proportion of bites these fish had directed toward the Daphnia in the Plexiglas cell on the day before ( $r=-0.44, n=44, P<0.003$, two-tailed). Thus, they had chosen (unreachable) Daphnia in Exp. 1 according to their ability to handle them. The ability to handle Daphnia correlated significantly with the size of these fish. The time needed per 


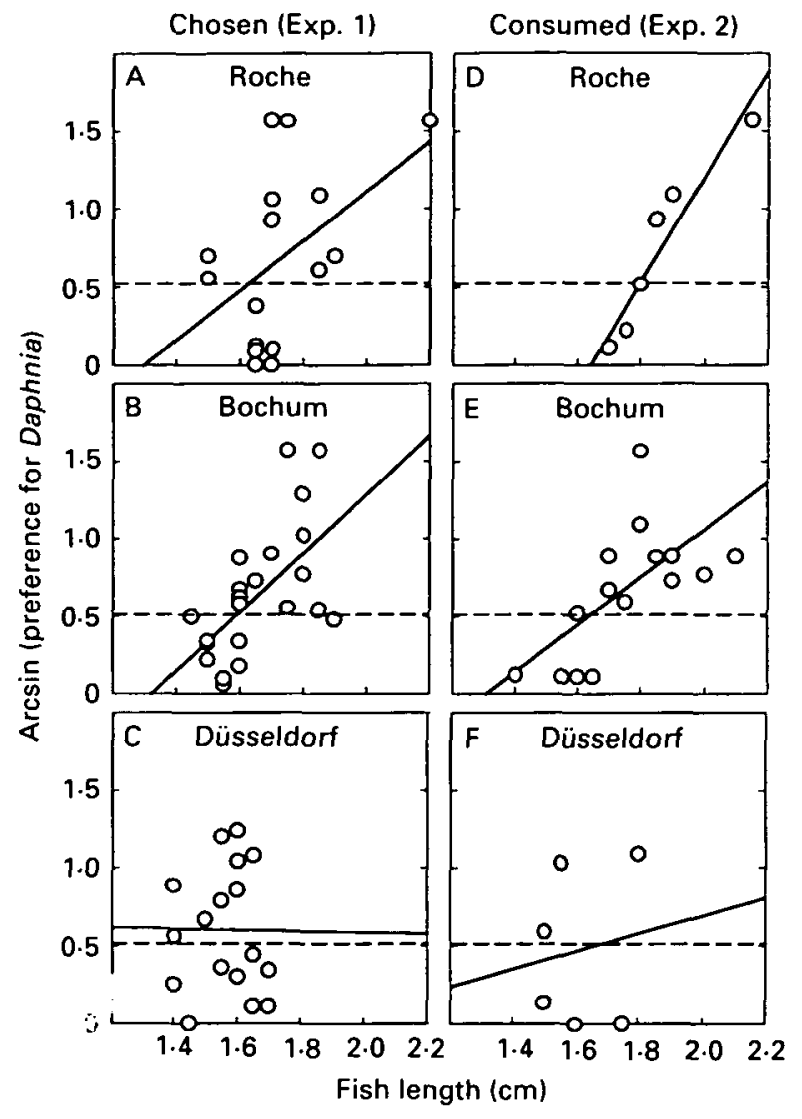

Fig. 3. Correlation between length of fish and (arcsin transformed) proportion of (A-C) bites on Daphnia in Exp. 1 or (D-F) Daphnia consumed in Exp. 2 by fish bred from each of 3 populations, i.e. Roche (no Schistocephalus solidus), Bochum and Düsseldorf (both with $S$. solidus); line gives linear regression, stippled line depicts no preference.

consumed Daphnia was longer for smaller than for larger fish $(r=-0.38, n=53, P<0.006$, twotailed). Was the preference for Daphnia in the experimental cell also dependent on the fish's size? Also the proportion of bites these fish had directed toward the Daphnia in the Plexiglas cell on the day before correlated significantly with their size $(r=$ $0.39, n=56, P<0.003$, two-tailed). Thus, larger fish preferred Daphnia and smaller fish copepods when they had the choice.

Do sticklebacks from the infected populations switch at a smaller size from preferring copepods to preferring Daphnia than fish from the uninfected population? Whereas sticklebacks from the uninfected population in Roche (Fig. $3 \mathrm{~A})\left(r_{s}=0.53\right.$, $n=16, P=0.04$, two-tailed) and from the infected population in Bochum (Fig. $3 \mathrm{~B}$ ) showed a significant correlation between size and preference for Daphnia ( $r_{s}=0.67, n=23, P=0.001$, two-tailed), no such correlation could be detected in fish from the other infected population in Düsseldorf (Fig. 3C) $\left(r_{s}=\right.$ $-0.08, n=17, P=0.76$, two-tailed). Sticklebacks from the 3 populations did not differ in their sizerelated preference for Daphnia over copepods
(ANCOVA, effect of population: $F=0.51$, D.F. $=2$, $P=0.60$; effect of fish length: $F=13.57$, D.F. $=1$, $P=0.0005$; interaction between fish length and population not significant: $P=0 \cdot 27$ ).

\section{Experiment 2 : hunting copepods and Daphnia by sticklebacks}

Did the sticklebacks prefer infected rather than uninfected copepods also when they could actually hunt and consume them? Although the 3 series $(a-c)$ of this experiment differed to some extent in the methods used and were separated by more than a year, the results were very similar and significant in each case: the sticklebacks consumed preferentially infected copepods (Table 1) (combined probabilities of series a-c: $\chi^{2}=17 \cdot 1$, D.F. $=6$, two-tailed, $P<$ $0.01)$. When we reanalysed the results of the study of Urdal et al. (1995), that had been performed with three-spined sticklebacks and copepods (Cyclops scutifer) infected with $S$. solidus, we found also a significant preference for infected copepods (Table 1)(combined probabilities of series a-c and the Urdal et al. (1995) study: $\chi^{2}=24 \cdot 3$, D.F. $=8$, two-tailed, $P<0.005)$. The observed preference for infected copepods did not differ significantly among the 4 independent series (ANOVA: $F=0.07, D . F .=3$, $P,=0.97)$.

Did the sticklebacks prefer Daphnia rather than uninfected copepods when they could actually hunt and consume them? In which order did they consume Daphnia and copepods, when they hunted both prey types? Do they prefer Daphnia rather than copepods according to their own size, i.e. their ability to handle them as in Exp. 1? The larger sticklebacks ( $>1.75 \mathrm{~cm}, n=14)$ consumed more Daphnia than copepods (one-sample $t$-test, twotailed: $t=8.69$, D.F. $=13, P \ll 0.001$ ) whereas the smaller sticklebacks ( $\leqslant 1.75 \mathrm{~cm}, n=14$ ) consumed more copepods than Daphnia $(t=3 \cdot 13$, D.F. $=13$, $P<0.01$ ) (Fig. 4). These results confirm those from Exp. 1 when the fish could only choose but not consume Daphnia and copepods in Exp. 1.

Fish of both size classes consumed increasingly more copepods in the course of the trial (Fig. 4) (larger fish: directed G-test for heterogeneity, $\mathrm{G}=$ 7.71 , D.F. $=8, r_{s} P_{c}=0.44, p_{d i r}=0.04$; smaller fish: $\mathrm{G}=23.11$, D.F. $\left.=8, r_{s} P_{c}=0.85, p_{d i r}<0.001\right)$. Can this dynamic change of preference be explained from an optimal foraging point of view? The fish that had been supplied with 20 Daphnia each on the day after Exp. 1 needed increasingly more time to catch and consume a Daphnia from the 1 st to the 6 th item (Fig. $5 \mathrm{~A}$ ) (repeated measures two-way-ANOVA, $n=53$ : effect of sequence: $\mathrm{F}=12 \cdot 06$, D.F. $=4, P \ll 0.001$ ). Larger fish ( $\geqslant 1.65 \mathrm{~cm}, n=29$, average size in whole sample: $1.64 \mathrm{~cm}$ ) needed less time than smaller fish $(<1.65 \mathrm{~cm}, n=24$ ) (effect of size class: $F=5.35$, D.F. $=1, P<0.025$ ). It seemed as if the fish 
Table 1. Number of copepods (no. of infected copepods) that were either consumed by sticklebacks or were left in the tank

(The copepod Macrocyclops albidus was used in series (a)-(c); Urdal et al. (1995) used Cyclops scutifer; data were taken from their Fig. 3.)

\begin{tabular}{|c|c|c|c|c|c|}
\hline Series & $\begin{array}{l}\text { Fish } \\
\text { no. }\end{array}$ & Consumed & $\begin{array}{l}\text { Left in } \\
\text { the tank }\end{array}$ & $\begin{array}{l}\text { Observed/ } \\
\text { expected }\end{array}$ & $\begin{array}{l}\text { Wilcoxon } \\
\text { one-sample test* }\end{array}$ \\
\hline (a) & $\begin{array}{l}1 \\
2 \\
3 \\
4\end{array}$ & $\begin{array}{r}10(7) \\
8(5) \\
9(6) \\
5(3)\end{array}$ & $\begin{array}{r}8(2) \\
10(4) \\
9(3) \\
7(3)\end{array}$ & $\begin{array}{l}1 \cdot 4 \\
1 \cdot 25 \\
1 \cdot 33 \\
1 \cdot 2\end{array}$ & $P=0.043$ \\
\hline (b) & $\begin{array}{l}5 \\
6 \\
7 \\
8 \\
9\end{array}$ & $\begin{array}{r}2(2) \\
13(7) \\
11(6) \\
12(7) \\
10(5)\end{array}$ & $\begin{array}{r}18(8) \\
7(3) \\
9(4) \\
8(3) \\
10(5)\end{array}$ & $\begin{array}{l}2 \\
1.08 \\
1.09 \\
1 \cdot 17 \\
1\end{array}$ & $P=0.043$ \\
\hline (c) & $\begin{array}{l}10 \\
11 \\
12 \\
13 \\
14 \\
15\end{array}$ & $\begin{array}{r}11(1) \\
10(1) \\
10(2) \\
10(2) \\
8(2) \\
6(3)\end{array}$ & $\begin{array}{l}4(0) \\
1(0) \\
1(0) \\
0 \\
4(0) \\
2(0)\end{array}$ & $\begin{array}{l}1 \cdot 36 \\
1 \cdot 1 \\
1 \cdot 1 \\
- \\
1 \cdot 5 \\
1 \cdot 33\end{array}$ & $P=0.026$ \\
\hline Data $\mathrm{fr}$ & $\begin{array}{c}\text { Urda } \\
1 \\
2 \\
3 \\
4 \\
5 \\
6 \\
7 \\
8 \\
9\end{array}$ & $\begin{array}{l}a l .(1995) \\
3(2) \\
4(2) \\
9(4) \\
5(3) \\
9(6) \\
9(5) \\
7(4) \\
2(1) \\
1(1)\end{array}$ & $\begin{array}{l}17(8) \\
16(8) \\
11(6) \\
15(7) \\
11(4) \\
11(5) \\
13(6) \\
18(9) \\
19(9)\end{array}$ & $\begin{array}{l}1 \cdot 33 \\
1 \\
0 \cdot 89 \\
1 \cdot 2 \\
1 \cdot 33 \\
1 \cdot 11 \\
1 \cdot 14 \\
1 \\
2\end{array}$ & $P=0.017$ \\
\hline
\end{tabular}

* Directed

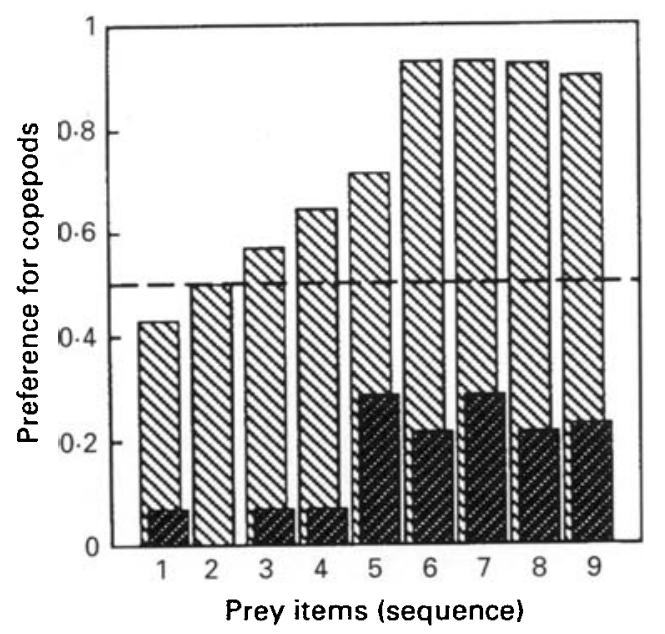

Fig. 4. Proportion of copepods consumed by smaller (light bars) and larger (dark bars) sticklebacks shown for the first to the 9 th prey item consumed, respectively; a mixture of 9 copepods and 9 Daphnia had been offered; stippled line depicts no preference.

increasingly had difficulties in swallowing a Daphnia. They 'chewed' a Daphnia for some time and spat it out and recaptured it up to 4 times. The number of captures per Daphnia increased from the 1 st to the 6th item (directed repeated measures ANOVA, F $=$ 1.82 , D.F. $\left.=5, r_{s} P_{c}=0.53, p_{d i r}=0.04\right)$. The smaller fish especially had problems. The number of captures for swallowing the 6 Daphnia correlated negatively with the size of the fish $(r=-0 \cdot 55, n=$ $55, P \ll 0 \cdot 001)$. Thus, Daphnia were easy to catch but increasingly difficult to swallow. Copepods were somewhat difficult to catch but easy to swallow. The fish that had hunted only copepods in Exp. 2 needed, after some difficulties at the beginning, always a similar time to catch and swallow the next copepod (Fig. 5B). The interaction between the time sequence of consuming the 2 nd to the 6 th Daphnia and the 2 nd and the 6 th copepod is significant (twoway repeated measures ANOVA: $\mathrm{F}=8 \cdot 88$, D.F. $=1$, $P<0.005$ ). It is, however, not significant if the time to consume the 2 nd copepod is excluded ( $F=1.49$, D.F. $=1, P=0.22$ ).

Do sticklebacks from the infected populations consume a higher proportion of Daphnia already at a smaller size than do fish from the uninfected population? The results were very similar to those from the choice experiment (Fig. 3A-C). Whereas sticklebacks from the uninfected population in Roche (Fig. 3D) $\left(r_{s}=1 \cdot 0, n=6, P=0 \cdot 01\right.$, two-tailed) and from the infected population in Bochum (Fig. $3 \mathrm{E}$ ) 

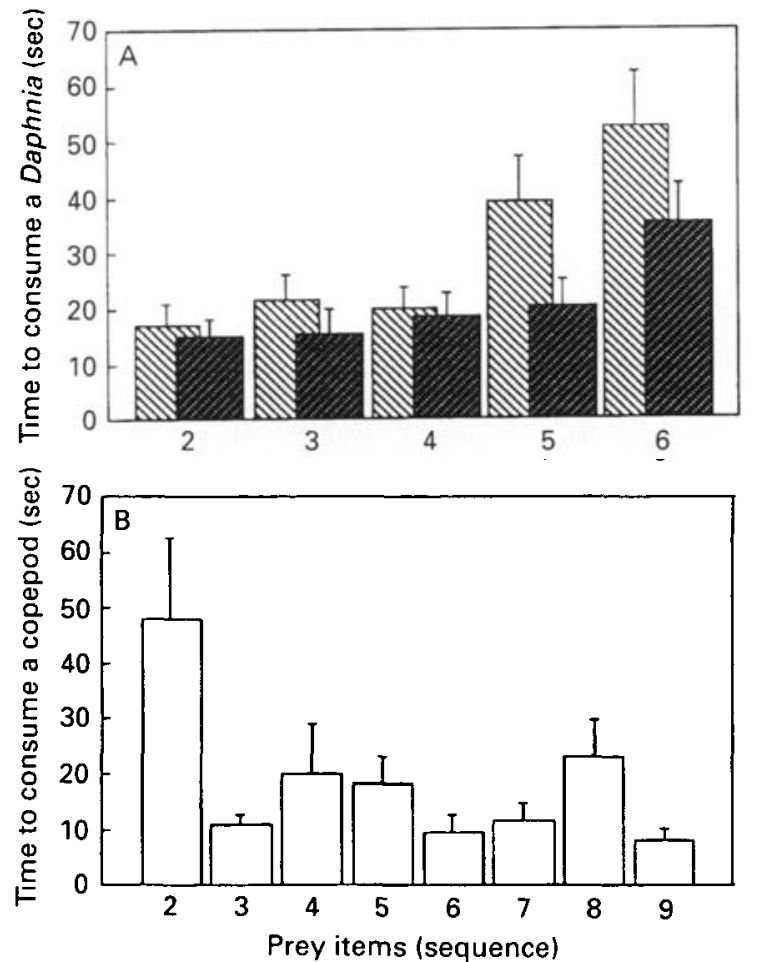

Fig. 5. Mean +S.E. time (sec) the sticklebacks needed to consume (A) the 2 nd to the 6 th out of 20 Daphnia, respectively (light bars: smaller, dark bars larger fish), (B) the 2 nd to the 9 th out of 18 copepods, respectively.

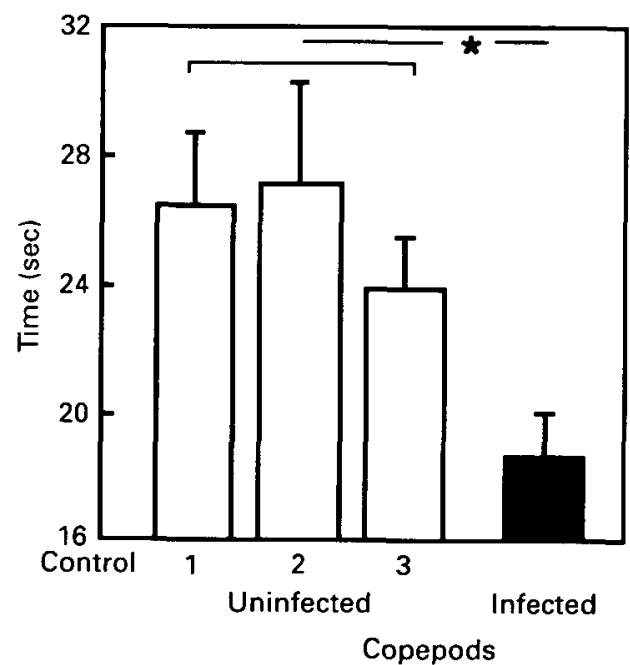

Fig. 6. Mean +s.E. time (sec) that uninfected copepods from 3 control groups ( $1: n=29$ exposed, screened; 2 : $n=13$ unexposed, screened; $3: n=16$ unexposed, unscreened) and infected ones $(n=12)$ resisted a water current; * depicts $P<0.05$.

$\left(r_{s}=0.64, n=17, P=0.01\right.$, two-tailed) showed a significant correlation between size and preference for Daphnia , no such correlation could be detected in fish from the other infected population in Düsseldorf (Fig. 3F) $\left(r_{s}=0.09, n=6, P=0.84\right.$, two-tailed). Again the sticklebacks from the 3 populations did not differ significantly in their sizerelated preference for Daphnia over copepods
(ANCOVA, effect of population: $\mathrm{F}=0 \cdot 29$, D.F. $=2$, $P=0.75$; effect of fish length: $F=15 \cdot 11$, D.F. $=1$, $P=0.0007$; interaction between fish length and population not significant: $P=0 \cdot 19$ ).

\section{Experiment 3 : hunting copepods by a human}

Only 4 of the 30 copepods of the first series had been infected; they tended to be caught earlier than uninfected copepods (Mann-Whitney U-test, $n_{1}=$ $4, n_{2}=26, \mathrm{U}=77 \cdot 9, P=0 \cdot 127$, two-tailed). In the second series 40 of the 106 copepods were infected and were caught significantly earlier than uninfected copepods (Mann-Whitney U-test, $n_{1}=40, n_{2}=66$, $\mathrm{U}=1657 \cdot 0, P=0.028$, two-tailed). Also when the probabilities from both series were combined infected copepods were caught significantly earlier than uninfected ones $\left(\chi^{2}=11.27\right.$, D.F. $=4, P<$ 0.025 , two-tailed). Larger copepods were caught sooner than smaller ones (first series: $r_{s}=0.63, n=$ $30, P<0.001$; second series: $r_{s}=0.24, n=106, P=$ $0 \cdot 013)$ although infected copepods did not differ in size-class from uninfected ones (Mann-Whitney Utest, two-tailed: first series: $\mathrm{U}=57.5, P=0.68$; second series: $U=1366 \cdot 5, P=0.73)$. Infected copepods carried between 1 and 6 procercoids which did, however, not influence the sequence of capture $\left(r_{s}=\right.$ $0.07, n=40, P=0.72$ )

\section{Experiment $4:$ infected and uninfected copepods in a current}

Copepods with procercoids passed more quickly through the channel than did uninfected control copepods (ANOVA: $\mathrm{F}=5.62$, D.F. $=1, P=0.02$, two-tailed) (Fig. 6); there was no significant difference among the 3 control groups (ANOVA: $F=$ $0 \cdot 46$, D.F. $=2, P=0 \cdot 63$, two-tailed). Thus, infected copepods appeared to be weaker than uninfected ones because of their infection and not vice versa; their weakness was not significantly affected by being handled for inspection under the microscope. Direct observation confirmed that the infected copepods tried, as did uninfected ones, to swim against the current. They were, however, less successful than those.

\section{Experiment 5 : reaction to predation}

After being transferred to the test tank, 7 out of 17 infected copepods ( $41 \%$ ) swam immediately to the water surface and stayed there, whereas only 2 out of 71 uninfected copepods $(3 \%)$ displayed this behaviour (Fig. $7 \mathrm{~A}$ ) (exact Fisher test: two-tailed, $P<$ $0.0001)$. Most $(=72)$ of the 79 copepods that had not moved to the water surface reacted with flight to the simulated stickleback attack. The flight ended at the surface in 2 of 8 infected and 3 out of 64 uninfected copepods (Fig. 7B)(exact Fisher-test: two-tailed, 


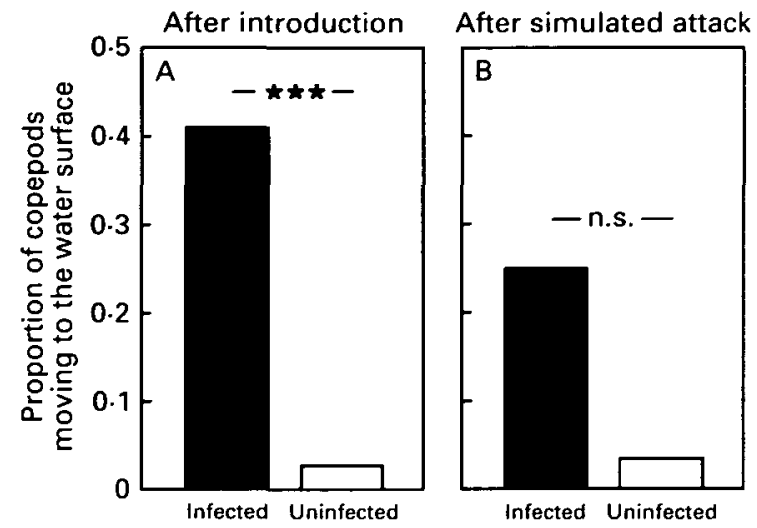

Fig. 7. Proportion of infected and uninfected copepods that moved to the water surface (A) after being pipetted to a tank, (B) after a simulated stickleback attack; $* * *$ depicts $P<0.001$.

$P=0 \cdot 09$. Thus, infected copepods tended to move more often to the surface than did uninfected ones after a simulated attack. With regard to the distance moved, there was no significant difference between infected and uninfected copepods neither after being transferred to the tank (ANOVA, F $=0.72$, D.F. $=1$, $P=0.40$ ) nor after the simulated stickleback attack (ANOVA, F $=0 \cdot 12$, D.F. $=1, P=0.74$ ). There was no significant difference among the 3 control groups (after being transferred: ANOVA, F $=0.65$, D.F. $=$ 2, $P=0.51$; after simulated attack: ANOVA, $\mathrm{F}=$ $0 \cdot 50$, D.F. $=2, P=0.61$ )

\section{DISCUSSION}

For an optimal foraging approach to the question of whether three-spined sticklebacks should include copepods that are parasitized with $S$. solidus in their diet, the profitability in terms of energy content per handling time needs to be determined for both parasitized and unparasitized copepods. Because we found no difference in size between infected and non-infected copepods 3 weeks p.i. (Exp. 3), we assume that the energy content is only slightly lower in infected copepods because the procercoid may only sometimes be digestible. Also neither Poulin et al. (1992) nor Pasternak et al. (1995) found a significant size difference between copepods that were infected with procercoids of Eubothrium salvelini or Diphyllobothrium spp., respectively, and non-infected controls.

Is there any difference in handling time (i.e. the time from the start of approaching a prey item until it is swallowed) between infected and non-infected copepods? Because the sticklebacks' preference or avoidance of parasitized prey may affect their handling time, we used naive and untrained human predators that either hunted copepods with a pipette (Exp. 3) or attacked them with a dummy stickleback (Exp. 5). Infected copepods were much easier to catch (a similar result was obtained by Pasternak, Huntingford \& Crompton (1995) for Diphyllobothrium spp.) and were therefore caught before unparasitized ones. There was no difference with respect to the distance they moved after a simulated stickleback attack between infected and non-infected copepods; however, infected copepods tended to flee more often to the water surface, which might facilitate a second attack and thus reduce the predator's handling time. Poulin et al. (1992) found no difference in time spent near the surface between copepods that were infected with Eubothrium salvelini and non-infected controls. Because of the infection with $S$. solidus parasitized copepods were weaker swimmers than uninfected controls when they tried to swim against a water current (Exp. 4). This weakness would also affect the infected copepods' escape ability, which might be the causal explanation for the result that infected copepods were easier to catch. We may conclude that copepods that are infected with $S$. solidus have a higher energy content per handling time and were thus a more profitable prey than non-parasitized copepods. If we overestimated the energy content of parasitized copepods because their tissue contained less energy per unit volume caused by the energy drain to the parasite, the evolution of a behavioural resistance in sticklebacks would be more likely.

If a prey type is caught more frequently because it is easier to catch than another prey type, we need not assume that the predator 'prefers' one prey type over the other. Therefore we removed the difference in catchability by offering three-spined sticklebacks a simultaneous choice between infected and noninfected copepods that were both unreachable by being confined in a Plexiglas cell (Exp. 1). Parasitized copepods were preferentially attacked. They moved a greater proportion of time as had been found in copepods infected with $S$. solidus by Urdal et al. (1995) and with Eubothrium salvelini by Poulin et al. (1992); Pasternak et al. (1995), however, found that copepods infected with Diphyllobothrium spp. were less active than uninfected controls. If a parasitized prey is more active and predators attack that prey more frequently, it is usually implied that there is a causal relationship between prey activity and predator attack probability. We have demonstrated the existence of this causal relationship for the first time. Within a trial both infected and uninfected copepods were attacked more often when they were active. Why should a predator attack active prey? Although we have seen many times that sticklebacks attacked copepods that did not move, prey activity might facilitate detection. Activity does not per se enhance a prey's profitability. Perhaps the parasite has altered not only the amount but also the form of the copepods' movements. We found that parasitized copepods were significantly more often attacked per unit of activity than were non-infected copepods. 
This suggests either that the parasitized copepods' form of movement was haltered and perhaps signals a lower escape ability or that the sticklebacks remained closer to the copepods that moved more often and thus attacked infected ones with a higher probability. We cannot yet decide between these alternatives.

When the sticklebacks could actually hunt in a mixture of infected and non-infected copepods (Exp. $2)$, they caught significantly more infected than noninfected copepods. 'The degree of 'preference' was similar under all conditions; it did not seem to matter whether the copepods were screened (handled), whether they had days or minutes to settle in the test tank or whether there were plants and sand as refuge. Also a re-analysis of the data of Urdal et al. (1995) revealed a significant preference for infected copepods at a similar level; their conclusion that $S$. solidus does not alter the predation susceptibility of infected copepods must be changed. Also Poulin et al. (1992) found that copepods that were parasitized with Eubothrium salvelini were more frequently consumed by brook trout.

When the fish had the choice between non-infected copepods and size-matched Daphnia (Exp. 1), the Daphnia were more active than the copepods but received fewer attacks per unit activity than the copepods. This shows that sticklebacks do not only take activity into account when they decide which type of prey to attack. We found a positive correlation between the sticklebacks' size-dependent ability to swallow Daphnia on the next day and their preference for unreachable Daphnia in the cell. The sticklebacks thus demonstrated a cognitive ability to prefer the prey type that they would handle more efficiently if they could reach it. When the sticklebacks could actually hunt in a mixture of Daphnia and non-infected copepods (Exp. 2), they demonstrated an optimal foraging solution: they started with Daphnia which, unlike copepods, were easy to catch but increasingly, when the stomach got filled, difficult to swallow, and switched to copepods. The smaller fish which had earlier difficulties with swallowing Daphnia switched earlier to copepods. This had the effect that on the whole larger fish preferred Daphnia and smaller fish preferred copepods. Gill \& Hart (1994) demonstrated that the profitability of different size classes of Asellus depended on the stomach fullness of three-spined sticklebacks and that the fish chose the optimal prey size with respect to their own size and the fullness of their stomach.

If the recognition of a parasitization of the copepods is difficult to achieve and therefore costly, the sticklebacks may avoid copepods irrespective of whether they are infected, when there is alternative prey. The dynamic fine-tuned preference either for Daphnia or copepods appears to be an optimal foraging solution that could easily be tuned to switching to copepods later in the hunting sequence. With regard to the stickleback's own size larger fish may avoid copepods in populations where copepods are highly risky food. We could not detect any difference between our laboratory bred fish whose parents came from populations which had a high prevalence of $S$. solidus infections and those whose parents came from an area in which $S$. solidus has never been detected. We found the same results for a choice between infected and non-infected copepods: parasitized copepods were invariably preferred. Although we have to be careful with our comparison among fish from only 3 different populations, we have to explain the fact that sticklebacks from 3 infected populations (including Urdal, Tierney \& Jakobsen's) significantly preferred parasitized copepods.

Why do the sticklebacks not avoid parasitized prey? If such an avoidance would require cognitive abilities that are outside the range of existing abilities, selection would be ineffective. At least for a rejection of copepods when alternative prey in the form of Daphnia is available the necessary cognitive abilities exist (see above). Perhaps alternative prey is so rare in these populations that behavioural resistance through adaptive choice could not evolve. This needs to be investigated. Genetic variation of susceptibility and resistance to disease has often been found both between and within host populations (Price, 1985; Chevassus \& Dorson, 1990) including genetic variation in behaviour (Yan, Stevens \& Schall, 1994). However, there may be additive genetic variation in physiology but no such variation in discriminative feeding behaviour (Berenbaum \& Zangerl, 1992). If the sticklebacks have a strong immune response so that they can fight the parasite effectively after ingestion, they need not avoid energetically profitable but infected prey. The high prevalence of $S$. solidus in both the Bochum and the Düsseldorf population demonstrates that the fish cannot efficiently avoid the parasite after ingestion. Several sticklebacks that had been caught in Düsseldorf (of an even smaller size than the average size used in this study had already established plerocercoids in their body cavity (C.W., personal observation). The usually high prevalence of $S$. solidus (Hopkins \& Smyth, 1951; Arme \& Owen, 1967; Threlfall, 1968; Chappell, 1969; Pennycuick, 1971; McPhail \& Peacock, 1983 ; personal observation) and the strong reduction of reproductive success at least in females (Arme \& Owen, 1967; Pennycuick, 1971; Meakins, 1974; McPhail \& Peacock, 1983) suggests that natural selection for the evolution of a behavioural resistance must exist. Female sticklebacks avoid to spawn with parasitized males (Milinski \& Bakker, 1990), why do they accept parasitized prey? There seems to be a paradox in the coevolution between $S$. solidus and its stickleback intermediate host. 
We thank Silvia López and Barbara Streb for labwork and help with Experiment 3, Dora Strahm and Maddalena Tognola for analysing the video-tapes of Experiment 1, Markus Frischknecht for coding the copepods in Experiments 4 and 5 , Julian Rauch for technical assistance, the referees for their comments, and the Swiss National Science Foundation for financial support.

\section{REFERENCES}

ARME, C. \& OWEN, R. W. (1967). Infections of the threespined stickleback, Gasterosteus aculeatus L., with the plerocercoid larvae of Schistocephalus solidus (Müller, 1776), with special reference to pathological effects. Parasitology 57, 301-14.

BAKKER, T. C. M. (1986). Aggressiveness in sticklebacks (Gasterosteus aculeatus L.): a behaviour-genetic study. Behaviour 98, 1-143.

BERENBAUM, M. R. \& ZANGERL, A. R. (1992). Genetics of physiological and behavioral resistance to host furanocoumarins in the parsnip webworm. Evolution 46, 1373-84.

CHAPPELL, L. H. (1969). Competitive exclusion between two intestinal parasites of the three-spined stickleback, Gasterosteus aculeatus L. Fournal of Parasitology 55, 775-8.

Chevassus, B. \& DORSON, M. (1990). Genetics of resistance to disease in fishes. Aquaculture 85, 83-107.

COMBEs, c. (1991). Ethological aspects of parasite transmission. The American Naturalist 138, 866-80.

CUNNINGHAM, E. J., TIERNEY, J. F. \& HUNTINGFORD F. A. (1994). Effects of the cestode Schistocephalus solidus on food intake and foraging decisions in the three-spined stickleback, Gasterosteus aculeatus. Ethology 97, 65-75.

DAWkins, R. (1990). Parasites, desiderata lists and the paradox of the organism. Parasitology 100, 63-73.

DOBSON, A. P. (1988). The population biology of parasiteinduced changes in host behavior. Quarterly Review of Biology 63, 139-65.

EMLEN, J. M. (1966). The role of time and energy in food preference. The American Naturalist 100, 611-17.

GILES, N. (1983). Behavioural effects of the parasite Schistocephalus solidus (Cestoda) on an intermediate host, the three-spined stickleback, Gasterosteus aculeatus L. Animal Behaviour 31, 1192-4.

GILES, N. (1987). Predation risk and reduced foraging activity in fish: experiments with parasitized and nonparasitized three-spined sticklebacks, Gasterosteus aculeatus L. Fournal of Fish Biology 31, 37-44.

GILL, A. B. \& HART, P. J. B. (1994). Feeding behaviour and prey choice of the three-spine stickleback: the interaction effects of prey size, fish size and stomach fullness. Animal Behaviour 47, 921-32.

HART, B. L. (1994). Behavioural defense against parasites: interaction with parasite invasiveness. Parasitology 109 (Suppl.), S139-S151.

HOLMES, J. C. \& BETHEL, w. M. (1972). Modification of intermediate host behaviour by parasites. In Behavioural Aspects of Parasite Transmission (ed. Canning, E. U. \& Wright, C. A.). Zoological fournal of the Linnean Society 51, 123-49.

HOLNes, J. C. \& zoHaR, s. (1990). Pathology and host behaviour. In Parasitism and Host Behaviour (ed. Barnard C. J. \& Behnke J. M.), pp. 34-94. London: Taylor \& Francis.
HOPKINS, C. A. \& SMYTH, J. D. (1951). Notes on the morphology and life history of Schistocephalus solidus (Cestoda: Diphyllobothridae). Parasitology 41, 283-91.

HLLSCHER, J. B. (1973). Burying-depth and trematode infection in Macoma balthica. Netherlands fournal of Sea Research 6, 141-56.

KEYMER, A. D., CROMPTON, D. W. T. \& SAHAKIAN, B. J. (1983). Parasite-induced learned taste aversion involving Nippostrongylus in rats. Parasitology 86, $455-60$.

KEYMER, A. D. \& READ, A. F. (1991). Behavioural ecology: the impact of parasitism. In Parasite-Host Associations : Coexistence or Conflict? (ed. Toft, C. A., Aeschliman, A. \& Bolis, L.), pp. 37-61. Oxford: Oxford University Press.

LAFFERTY, K. D. (1992). Foraging on prey that are modified by parasites. The American Naturalist 140 , 854-67.

LOZANO, G. A. (1991). Optimal foraging theory - a possible role for parasites. Oikos 60, 391-5.

MACARTHUR, R. H. \& PIANKA, E. R. (1966). On optimal use of a patchy environment. The American Naturalist 100, 603-9.

MAY, R. M. \& ANDERSON, R. M. (1990). Parasite-host coevolution. Parasitology 100, 271-318.

McPHAIL, J. D. \& PEACOCK, S. D. (1983). Some effects of the cestode (Schistocephalus solidus) on reproduction in the threespine stickleback (Gasterosteus aculeatus): evolutionary aspects of a host-parasite interaction. Canadian fournal of Zoology 61, 901-14.

MEAKINS, R. H. (1974). A quantitative approach to the effects of the plerocercoid of Schistocephalus solidus Müller 1776 on the ovarian maturation of the threespined stickleback Gasterosteus aculeatus L. Zeitschrift für Parasitenkunde 44, 73-9.

MEAKINS, R. H. \& WALKEY, M. (1973). Aspects of in vivo growth of the plerocercoid stage of Schistocephalus solidus. Parasitology 67, 133-41.

MiLINSKI, M. (1984). Parasites determine a predator's optimal feeding strategy. Behavioral Ecology and Sociobiology 15, 35-7.

MILINSKI, M. (1985). Risk of predation of parasitized sticklebacks (Gasterosteus aculeatus L.) under competition for food. Behaviour 93, 203-16.

MILINSKI, M. (1990). Parasites and host decision-making. In Parasitism and Host Behaviour (ed. Barnard, C. J. \& Behnke, J. M.), pp. 95-116. London: Taylor \& Francis.

MILINSKI, M. \& BAKKER, T. C. M. (1990). Female sticklebacks use male coloration in mate choice and hence avoid parasitized males. Nature, London 344, 330-3.

MILINSKI, M. \& HELLER, R. (1978). Influence of a predator on the optimal foraging behaviour of sticklebacks (Gasterosteus aculeatus L.). Nature, London 275, 642-4.

MINCHELLA, D. J. (1985). Host life-history variation in response to parasitism. Parasitology 90, 205-16.

MiNCHELLA, D. J. \& LOVERDE, P. T. (1983). Laboratory comparison of the relative success of Biomphalaria glabrata stocks which are susceptible and insusceptible to infection with Schistosoma mansoni. Parasitology 86, $335-44$. 
MOORE, J. (1983). Responses of an avian predator and its isopod prey to an acanthocephalan parasite. Ecology 64, 1000-15.

MOORE, J. (1984). Parasites that change the behavior of their host. Scientific American 250, 82-9.

MOORE, J. (1995). The behavior of parasitized animals. BioScience 45, 89-96.

MOORE, J. \& Gotelli, N. J. (1990). Phylogenetic perspective on the evolution of altered host behaviours: a critical look at the manipulation hypothesis. In Parasitism and Host Behaviour (ed. Barnard, C. J. \& Behnke, J. M.), pp. 193-229. London: Taylor \& Francis.

ORR, T. S. C. \& HOPKINS, C. A. (1969). Maintenance of Schistocephalus solidus in the laboratory with observations on rate of growth of, and proglottid formation in, the plerocercoid. Fournal of the Fisheries Research Board Canada 26, 741-52.

PASCOE, D. \& MATTEY, D. (1977). Dietary stress in parasitized and non-parasitized Gasterosteus aculeatus L. Zeitschrift für Parasitenkunde 51, 179-86.

PASTERNAK, A. F., HUNTINGFORD, F. A. \& CROMPTON, D. W. T. (1995). Changes in metabolism and behaviour of the freshwater copepod Cyclops strenuus abyssorum infected with Diphyllobothrium spp. Parasitology 110, 395-9.

PENNYCUICK, L. (1971a). Quantitative effects of three species of parasites on a population of three-spined sticklebacks, Gasterosteus aculeatus. Fournal of Zoology $165,143-62$.

PENNYCuICK, L. (1971b). Differences in the parasite infections in three-spined sticklebacks (Gasterosteus aculeatus $\mathrm{L}$.) of different sex, age and size. Parasitology 63, 407-18.

POULIN, R. (1994). The evolution of parasite manipulation of host behaviour: a theoretical analysis. Parasitology 109 (Suppl.), S109-S118.

POULIN, R., CURTIS, M. A. \& RAU, M. E. (1992). Effects of Eubothritum salvelini (Cestoda) on the behaviour of Cyclops vernalis (Copepoda) and its susceptibility to fish predators. Parasitology 105, 265-71.
PRICE, D. J. (1985). Genetics and susceptibility and resistance to disease in fishes. Journal of Fish Biology 26, 509-19.

RANTA, E. (1995). Schistocephalus infestation improves prey-size selection by three-spined sticklebacks. Fournal of Fish Biology 46, 156-8.

SMYTH, J. D. (1954). Studies on tapeworm physiology. VII. Fertilization of Schistocephalus solidus in vitro. Experimental Parasitology 3, 64-71.

SuYth, J. D. (1985). Introduction to Animal Parasitology. London: Hodder and Stoughton.

STEPHENS, D. W. \& KREBS, J. R. (1987). Foraging Theory. Princeton: University Press.

Thompson, s. N. \& Kavaliers, M. (1994). Physiological bases for parasite-induced alterations of host behaviour. Parasitology 109 (Suppl.), S119-S138.

THRELFALL, w. (1968). A mass die-off of three-spined sticklebacks (Gasterosteus aculeatus L.) caused by parasites. Canadian fournal of Zoology 46, 105-6.

TIERNEY, J. F., HUNTINGFORD, F. A. \& CROMPTON, D. W. T. (1993). The relationship between infectivity of Schistocephalus solidus (Cestoda) and anti-predator behaviour of its intermediate host, the three-spined stickleback, Gasterosteus aculeatus. Animal Behaviour 46, 603-5.

TOSCANELli, B. (1992). Die Beutewahl von juvenilen Stichlingen (Gasterosteus aculeatus) unter dem Einfluss des Parasitierungsrisikos. Thesis, Universität Bern.

URDAL, K., TIERNEY, J. F. \& JAKobSEN, P. J. (1995). The tapeworm Schistocephalus solidus alters the activity and response, but not the predation susceptibility of infected copepods. Journal of Parasitology 81, 330-3

WALKEY, M. \& MEAKINS, R. H. (1970). An attempt to balance the energy budget of a host-parasite system Fournal of Fish Biology 2, 361-2.

YAN, G., STEvens, L. \& SCHALl, J. J. (1994). Behavioral changes in Tribolium beetles infected with a tapeworm, variation in effects between beetle species and among genetic strains. The American Naturalist $143,830-47$. 